\title{
Apraxia da fala na infância em foco: perspectivas teóricas e tendências atuais $* * * *$
}

\author{
Childhood speech apraxia in focus: theoretical perspectives and \\ present tendencies
}

\author{
Thaís Nobre Uchôa Souza* \\ Luzia Miscow da Cruz Payão** \\ Ranilde Cristiane Cavalcante Costa***
}

\begin{abstract}
*Fonoaudióloga. Especialização em Linguagem pela Faculdade de

Odontologia de Bauru da Universidade de São Paulo. Fonoaudióloga da

Faculdade de Fonoaudiologia de Alagoas - Universidade Estadual de Ciências da Saúde de Alagoas. Endereço para correspondência: Rua Manoel Ribeiro da Rocha, 26 - Apto. 101 - Maceió - AL - CEP 57035-395 (thaisnobre@hotmail.com).

**Fonoaudióloga. Mestre em Lingüística pela Universidade Federal de Alagoas. Professora Assistente da Faculdade de Fonoaudiologia de Alagoas - Universidade Estadual de Ciências da Saúde de Alagoas.

***Fonoaudióloga. Especialização em Docência do Ensino Superior - Ibesa. Professora Auxiliar da Faculdade de Fonoaudiologia de Alagoas Universidade Estadual de Ciências da Saúde de Alagoas.

*****Trabalho Realizado na Faculdade de Fonoaudiologia de Alagoas da Universidade Estadual de Ciências da Saúde de Alagoas.
\end{abstract}

Artigo de Revisão de Literatura

Artigo Submetido a Avaliação por Pares

Conflito de Interesse: não

Recebido em 18.05.2008.

Revisado em 26.07.2008; 24.08.2008;

07.11.08.

Aceito para Publicação em 03.02.2009.

\begin{abstract}
Background: the appearance of the praxis disorder during the firsts years of development has been frequently designated as chidhood apraxia of speech. The present theoretical perspectives direct the speech therapist to new tendencies regarding therapeutic intervention. Aim: to present a bibliographic review of the last two years about chidhood speech apraxia. Conclusion: the present literature about childhood speech apraxia indicates an inclination among the researches that may motivate a mixed therapeutic broaching, in which one contemplates not only aspects pertinent to language processing in a phonological representational level, but alslo aspects related to motor programming and pre-articulatory sequencing of speech itself.
\end{abstract}

Key Words: Apraxia; Speech; Language.

\section{Resumo}

Tema: o aparecimento da desordem práxica durante os primeiros anos do desenvolvimento infantil tem sido freqüentemente denominado de apraxia da fala na infância. As perspectivas teóricas atuais direcionam o fonoaudiólogo a novas tendências em relação à intervenção terapêutica. Objetivo: realizar revisão bibliográfica sobre a apraxia da fala na infância nos últimos anos. Conclusão: constata-se nos textos atuais sobre apraxia de fala na infância uma tendência das pesquisas que poderá desencadear uma abordagem terapêutica mista, na qual se contemple tanto os aspectos pertinentes ao processamento de linguagem num nível representacional fonológico, quanto os aspectos pertencentes ao nível de programação motora e de seqüenciamento pré-articulatório da fala propriamente dita.

Palavras-Chave: Apraxias; Fala; Linguagem. 


\section{Introdução}

O desenvolvimento da fala da criança ocorre de forma gradual, respeitando as etapas de maturação e por isso ocupando grande parte da infância. Sabese que as crianças não nascem com os movimentos de fala já desenvolvidos e, portanto, não apresentam a praxia desenvolvida.

Os movimentos de lábios, língua e mandíbula sofrem modificações, e os movimentos indiferenciados no início da infância passam a ser refinados e diferenciados conforme $\mathrm{O}$ desenvolvimento. Essas transformações também são fundamentais para alcançar níveis mais elevados de precisão e coordenação articulatória, importantes para a efetividade da comunicação oral ${ }^{1}$.

Os gestos articulatórios de lábios superior, inferior e mandíbula apresentam mudanças significativas durante os primeiros anos de vida e continuam o seu refinamento até depois dos seis anos $^{2}$. O desenvolvimento do controle motor desses articuladores segue um curso não uniforme, com mandíbula precedendo o lábio. Este processo de desenvolvimento e refinamento do controle motor oral influencia significativamente na aquisição de sons da fala ${ }^{3}$.

Quando este refinamento não ocorre, a produção da fala torna-se comprometida, podendo surgir a suspeita de uma desordem práxica na infância. Esta desordem na infância é definida como uma suposta categoria diagnóstica atribuída às crianças, cujos erros de fala diferem dos erros de crianças com atraso no desenvolvimento de fala e se assemelham aos erros de adultos com apraxia adquirida ${ }^{4}$.

Os pacientes com apraxia da fala adquirida demonstram, geralmente, comprometimento primariamente na articulação, com alterações na seqüência dos movimentos musculares para a produção voluntária dos fonemas e, secundariamente, por alterações prosódicas, caracterizadas por uma fala mais lenta que o normal e com escassez de padrões de entonação, ritmo e melodia ${ }^{5}$. As anormalidades prosódicas são usualmente percebidas como sendo secundárias às dificuldades articulatórias. A falta da fluência na fala é causada por pausas e hesitações que ocorrem na tentativa de produzir corretamente as palavras, surgindo como uma forma de compensação da contínua dificuldade na articulação ${ }^{6}$.

$\mathrm{O}$ aparecimento da desordem práxica durante os primeiros anos do desenvolvimento infantil tem sido freqüentemente denominado de apraxia da fala desenvolvimental (Developmental Apraxia of Speech - DAS) ${ }^{4}$, dispraxia verbal desenvolvimental (Developmental Verbal Dyspraxia - DVD) ${ }^{7}$ ou apraxia da fala na infância (Childhood Apraxia of Speech-CAS) ${ }^{8}$.

A partir de revisão de literatura restrita e criteriosa sobre os fundamentos científicos em apraxia na infância, publicados desde 1995, a American SpeechLanguage-Hearing Association (ASHA) Ad Hoc Committee on Apraxia of Speech in Children adotou no ano de 2007 o termo CAS para se referir a todas as apraxias que se manifestam na infância. CAS envolve e unifica os estudos quanto aos procedimentos de avaliação e tratamento de todas as apresentações de apraxia de fala na infância. Assim, é recomendada a denominação CAS como preferível entre os termos alternativos DAS e DVD para esta alteração de fala. Os contextos clínicos de DAS e DVD estão, portanto, incorporados à CAS 9 .

CAS é definida como uma desordem neurológica dos sons da fala na infância, na qual a precisão e consistência dos movimentos que permeiam a fala estão prejudicadas na ausência de déficits neuromusculares. O principal impedimento manifesta-se no planejamento e/ou programação de parâmetros espaço-temporais das sequiências de movimentos, resultando em erros na produção dos sons da fala e prosódia?.

As apraxias em crianças podem indicar três contextos clínicos diferentes:

1. Podem estar associadas à etiologia neurológica conhecida (doença intra-uterina) infecções e trauma. 2. Ocorrem como sinal primário ou secundário em crianças com desordens neuro comportamentais complexas - genético, metabólico.

3. Não estar associada a qualquer desordem neurológica conhecida ou neuro comportamental complexa, mas associada a uma alteração dos sons da fala de origem neurogênica idiopática. Todos os três contextos clínicos compõem a CAS, terminologia atualizada dessa desordem de fala em crianças ${ }^{9}$.

Estima-se que a prevalência dessa desordem na população seja da ordem de $1-2$ por $1000^{10}$, e que a proporção média entre meninos e meninas seja tão alta quanto 9:17. Embora a CAS ocorra mais freqüentemente em meninos do que em meninas, quando ela se apresenta no sexo feminino sua manifestação é sempre mais severa ${ }^{11}$.

Dentre a população estimada de $2,5 \%$ préescolares que apresentam alterações fonológicas de origem desconhecida, uma proporção de $5 \%$ dessas representam crianças com CAS, dados esses que resultam numa estimativa de $0,125 \%$ de 
crianças apráxicas na população como um todo ${ }^{10}$.

Estudo verificou que nove entre onze crianças com CAS (compreendidas na faixa etária de 6:2 a 7:9) apresentam, além do comprometimento na programação motora da fala, alterações de linguagem, e que $55 \%$ dessas crianças possuem membros da família com alterações de fala e de linguagem ${ }^{12}$.

Para verificar a relação familiar na CAS, crianças com suspeita de CAS e seus familiares foram submetidas a questionários e a testes de expressão oral e habilidades motoras. Os resultados demonstraram que a presença de alterações de fala e linguagem foi superior em famílias de crianças diagnosticadas com CAS do que em famílias de crianças com outros transtornos. Assim, a relação familiar para alterações nos sons da fala e de linguagem foi demonstrada em $86 \%$ dos casos, em que pelo menos um membro da família encontrava-se afetado ${ }^{13}$.

\section{Características gerais}

No período pré-verbal, as crianças com CAS são descritas como bebês silenciosos, pois tendem a não se engajar em jogos vocais e suas emissões iniciais tendem a não se desenvolver em sons diferenciados. $\mathrm{O}$ fato de serem bebês quietos sinaliza para a possibilidade de hipótese diagnóstica de $\mathrm{CAS}^{14}$.

O período para emissão dos primeiros vocábulos significativos em crianças com CAS pode acontecer dos 19 meses aos 4 anos de idade. A idade média para a combinação das primeiras palavras em sentenças de dois vocábulos ocorre também com atraso, aparecendo entre as idades de 33 meses a 7 anos $^{15}$.

Uma criança com CAS pode ser descrita como aquela que apresenta audição normal, usa expressões faciais, gestos, sons não-verbais, vocábulos isolados ou frases sociais com intento comunicativo. Não apresenta nenhuma anormalidade estrutural ou paralisia aparente do mecanismo oral, que poderia justificar a ausência de fala inteligível e é uma criança cujas habilidades de compreensão auditivas parecem adequadas para desenvolver comunicação oral. No entanto, são conhecidas pelo lento progresso nas intervenções terapêuticas ${ }^{16}$.

Observa-se na fala dessas crianças uma redução no ritmo, com segregação de sílaba, associada à percepção de isocronia ou tempo similar, sílabas e palavras segregadas ou não co articuladas, consideradas como correlatos prevalentes nos quadros de apraxia da fala. $O$ déficit rítmico pode ser altamente específico, comparado com o prejuízo no acento, que pode prevalecer em outros tipos de alterações comunicativas ${ }^{17}$.
As crianças com CAS apresentam considerável dificuldade na produção de fala e acurácia fonética, caracterizadas por lentidão, intermitência e variabilidade, representadas acusticamente por duração geral longa ou em segmentos. Observamse ainda a taxa de velocidade lenta, pausas variáveis e longas (quebras na fala) e inconsistência entre as produções ${ }^{18}$. A fala dos pacientes apráxicos apresenta uma restrita variação de acentuação no nível da palavra e na sentença, além da predominância de ressonância nasofaríngea ${ }^{19}$.

O estudo comparativo de perfis prosódicos e segmentais entre um grupo de 14 crianças com suspeita de CAS e outro grupo de 73 crianças com atraso de fala de origem desconhecida mostrou que o único domínio lingüístico que as diferenciou foi a presença de acentuação inapropriada em palavras e frases, caracterizando-se num padrão de perda de contraste prosódico. Os achados encontrados também sustentam a heterogeneidade dos perfis prosódicos associados com a apraxia na infância. Além disso, concluem que o déficit de acento nessa forma de apraxia encontra-se mais em níveis de representação fonológica do que dentro do seqüenciamento préarticulatório característico de déficit motor de fala ${ }^{20-21}$.

Os procedimentos analíticos baseados na fonologia métrica e utilização de medidas acústicas mostraram-se relevantes em pesquisa de avaliação da análise métrica processada por crianças com CAS, nas quais observaram padrão de acento de sentença inapropriado. Esse padrão acentual característico nas apraxias da infância tem sido proposto como marcador diagnóstico em relação a outras alterações de fala em crianças. Os padrões métricos lexicais encontrados nessa pesquisa não diferenciaram os dois grupos de crianças avaliados com atraso de fala e com apraxia na infância. No entanto, o estudo observou que as omissões de sílabas persistiram em idades muito mais tardias em crianças com CAS, em especial naquelas em que já tinham identificado como apresentando acento frasal inapropriado ${ }^{22}$.

Apesar do déficit na programação motora dos órgãos fonoarticulatórios mostrar-se como o principal comprometimento da CAS, raramente as crianças vivenciam problemas somente na produção de fala; muitas delas apresentam como conseqüência ou não da apraxia da fala atraso no desenvolvimento de linguagem, que pode manifestar-se em todos os domínios linguísticos, incluindo a linguagem escrita ${ }^{14}$.

A literatura descreve pesquisa realizada com o objetivo de examinar as diferenças de fala/linguagem e aprendizagem da linguagem escrita entre crianças com suspeita de CAS e crianças com outras dificuldades nos sons da fala na idade escolar. Dez 
crianças clinicamente diagnosticadas com CAS foram avaliadas dos anos pré-escolares até a idade escolar, sendo comparadas com crianças com alterações isoladas nos sons da fala $(n=15)$ e com crianças com alterações nos sons da fala e na linguagem $(n=14)^{8}$.

A comparação dos grupos revelou que, na idade pré-escolar, o grupo das crianças com CAS foi similar ao grupo de crianças com alterações nos sons da fala e na linguagem. No entanto, na idade escolar, o grupo de crianças com alterações nos sons da fala e na linguagem fez mais mudanças positivas na aprendizagem da linguagem do que o grupo com CAS. Esse estudo encontrou ainda que todas as crianças com CAS demonstraram comprometimentos de linguagem expressiva e receptiva persistentes, no entanto, as habilidades de linguagem receptiva encontravam-se consistentemente superiores às habilidades de linguagem expressiva ${ }^{8}$.

Também é válido ressaltar que há coexistência de problemas educacionais, os quais são geralmente apresentados como reflexo das dificuldades de estabelecer as relações necessárias entre a representação escrita das palavras e a representação interna que as crianças têm da palavra falada. Essas dificuldades trazem repercussões às demais habilidades lingüísticas. A falta de experiência no nível de produção de fala pode comprometer as experiências de leitura e reduzir a proficiência na leitura e escrita ${ }^{14}$.

Em levantamento realizado para verificar quais os critérios utilizados para o diagnóstico da CAS, foi detectada uma diversidade nas características descritas por 75 fonoaudiólogos. Das 50 manifestações mencionadas, apenas seis ocorreram em $51,5 \%$ das respostas dadas pelos participantes da pesquisa: as produções inconsistentes, as dificuldades motoras orais, a hesitação ao falar, a inabilidade para imitar sons, o aumento da dificuldade proporcional ao aumento da sentença e a dificuldade em produzir os sons em seqüência ${ }^{23}$.

Pela diversidade de características envolvidas nos quadros de apraxia na infância, ainda hoje é comum que crianças com CAS sejam confundidas com quadros de desvios fonológicos ou atrasos de linguagem. De fato, fonoaudiólogos experientes na área costumam associar a CAS a uma inexplicável falta de progresso no tratamento. Portanto, são duas as características desta patologia sobre as quais há aparente consenso na literatura: o início é precoce no desenvolvimento da criança e apresenta um curso de normalização de longo prazo ${ }^{4}$.

Investigações têm sido realizadas com o objetivo de buscar um marcador diagnóstico para a CAS, o qual trará implicações para a pesquisa e a prática clínicas. Essas investigações levantam a hipótese de que a CAS pode ser uma desordem de fala geneticamente transmitida ${ }^{4}$.

Pesquisas genéticas têm sido realizadas no intuito de descobrir o foco do problema da CAS, e dentre esses se destacam os estudos sobre o FOXP2 $2^{19}$.

Os estudos sobre o FOXP2 mais difundidos foram os realizados com uma família intitulada como Família KE. A metade dos membros da família tem um fenótipo largamente marcado por uma apraxia orofacial; todos os membros afetados relataram ter apraxia da fala; alguns tiveram comprometimentos de linguagem; outros tiveram seu desempenho verbal diminuído ou tiveram outros envolvimentos, e todos os membros afetados têm um ponto de mutação no gene FOXP2 $2^{24-25}$.

FOXP2 é o primeiro gene conhecido por ser envolvido no desenvolvimento de fala e linguagem. Está localizado no cromossomo humano 7q31, e é expresso extensamente no desenvolvimento neural bilateralmente (córtex, gânglio basal, tálamo, cerebelo), nas áreas associadas com os processos sensoriais e motores ${ }^{25}$.

Os estudos de imagens estruturais e funcionais fornecem informações cruciais para a compreensão da cadeia de eventos por meio dos quais um ponto de mutação no gene FOXP2 resulta nas alterações de fala e linguagem demonstradas pela família KE. Tais estudos indicam que o FOXP2 pode ser importante para o desenvolvimento de redes cerebrais que estão envolvidas na aprendizagem, planejamento e execução orofacial e, em particular, nas seqüências motoras para o discurso, bem como na realização manual e outras seqüências motoras ${ }^{26}$.

Até um biomarcador tornar-se disponível para identificar crianças que são verdadeiros positivos para CAS, propostas provisórias incluindo critérios para o diagnóstico continuam a aparecer, compondo a comumente denominada checklist ${ }^{27}$.

Pesquisadores da área utilizam como critério de seleção de crianças com CAS características que incluem as dificuldades no seqüenciamento de fonemas e sílabas, distúrbios prosódicos, deleção de consoantes, diminuição na capacidade de diadococinesia, comportamentos de ensaio e erro, aumento de erros em palavras polissilábicas, inconsistência na articulação com erros não-usuais em consoantes e vogais ${ }^{8}$.

As pesquisas mais atuais preconizam a determinação de um marcador diagnóstico para CAS que considere o processamento da fala ocorrendo em distintos estágios. Existem seis estágios envolvidos no processamento lingüístico, os quais ocorrem em três domínios básicos: Input, Organização e Output, que ilustram as possíveis localizações alternativas dos déficits de produção de fala em crianças com suspeita de $\mathrm{CAS}^{4}$ :

1. Nos processos de input estão incluídos estágios de processamentos temporais-auditivos e memoriais- 
perceptuais necessários para a aquisição da fonologia da língua ambiente.

2. Nos processos de organização está incluído um estágio representacional que reflete os primitivos segmentais e suprasegmentais de formas subjacentes; e um estágio transformacional que ajusta as formas subjacentes para detalhes morfofonêmicos, alofônicos e sociolingüísticos apropriados. Alguns esquemas teóricos consideram que esses dois níveis de processamento representam o conhecimento fonológico do falante. 3. Nos processos de output estão incluídos dois níveis: um para seleção-recuperação dos elementos fonológicos e outro nível para seqüenciamento préarticulatório. O estágio final de execução articulatória acrescenta qualquer déficit na integridade do mecanismo motor de fala proveniente dos produtos dos estágios prévios.

No planejamento fonológico e cognitivolingüístico podem estar envolvidos um ou mais de um dos cinco estágios de processamentos pertencentes ao input e à organização; enquanto que na programação fonética e motora da fala há o envolvimento do estágio mais baixo do output - de seqüenciamento pré-articulatório, assim como do estágio final de execução articulatória. Esses aspectos ilustram a diversidade de possibilidades quanto à natureza e origem da $\mathrm{CAS}^{4}$.

Em estudo desenvolvido com sete participantes, entre os quais se incluíam três crianças com suspeita de CAS, foram levantadas duas hipóteses. $\mathrm{Na}$ hipótese 1, seria a associação de déficit lingüístico; na hipótese 2 , foi levantado déficit no ritmo central para as imprecisões durante a fala. Esse estudo constou de medições na duração dos componentes subsilábicos - onset, núcleo e coda, usando o Praat 4.0.45, software para análise acústica, comparando os efeitos de duração vocálica intrínseca e extrínseca em palavras monossilábicas ${ }^{28}$.

Os resultados da análise acústica desses componentes possibilitaram descartar a hipótese de uma dificuldade específica de ordem lingüística em manipular os componentes subsilábicos que constituem as sílabas das palavras, como levantado na hipótese 1. Nas análises e discussões do estudo, foi relacionado o déficit de ritmo central, ou seja, a associação das imprecisões temporais na $\mathrm{CAS}^{28}$.

A análise acústica pode ser útil ao estudo da apraxia da fala, pois a fala do indivíduo com apraxia tende a ser lenta, intermitente e variável. As análises espectrográficas constatam as diferenças evidentes na duração de palavras, sendo duas vezes mais longas que em um falante com controle de fala normal. Os estudos da apraxia da fala com base acústica mostram variações de voice onset time (VOT) e erros com padrões fonéticos ${ }^{18}$.

Procedimentos de análise acústica foram utilizados para quantificar a regularidade temporal nos eventos de fala e nos de pausa em 75 crianças selecionadas em três grupos, para os quais se adotaram os seguintes critérios:

1. Composto por 30 crianças com aquisição de fala normal, variando de três a seis anos de idade.

2. Com 30 crianças apresentando atraso na fala, compreendendo a faixa etária de três a seis anos.

3. Constituído de quinze crianças com suspeita de CAS, com idade variando de três a qüatorze anos de idade ${ }^{17}$.

Os estudos interpretaram a restrição no tempo de fala como a característica mais importante da alteração práxica e que define uma forma de desenvolvimento de apraxia da fala. As técnicas acústicas adotadas nessa pesquisa tornaram a quantificação e medição dos dados de duração do tempo mais fáceis nos eventos de fala e nos eventos de pausa durante a conversação, delimitando uma característica importante da $\mathrm{CAS}^{17}$.

\section{Conclusão}

É importante conhecer detalhadamente o quadro complexo da CAS, bem como suas características, para que o tratamento fonoaudiológico seja planejado de forma adequada. A terapia apresenta-se como uma das mais difíceis dentro dos distúrbios de fala e de linguagem, pois é uma desordem rara, normalmente difícil de ser reabilitada, e geralmente os processos terapêuticos são longos.

Há consenso sobre a existência de déficit no controle motor voluntário dos órgãos fonoarticulatórios para a produção de fala. Além disso, a presença de alguns padrões de erros na fala, tais como simplificação de estrutura silábica, supressão de consoante final, supressão de consoante inicial, redução de encontro consonantal e plosivização é também analisada numa perspectiva lingüístico-fonológica.

No entanto, a ênfase apenas nessa perspectiva lingüístico-fonológica não se apresenta eficaz na clínica fonoaudiológica, uma vez que as práticas dos gestos essencialmente articulatórios não são reforçadas o suficiente nessa perspectiva terapêutica.

Constata-se nos textos atuais sobre CAS uma tendência das pesquisas que podem desencadear numa abordagem terapêutica mista, na qual se 
contemple tanto os aspectos pertinentes ao processamento de linguagem num nível representacional fonológico como os aspectos

\section{Referências Bibliográficas}

1. Meyer PG. Tongue lip and jaw differentiation and its relationship to orofacial myofunctional treatment. Int. J. Orofac. Myol. 2000;(26):44-52.

2. Green JR, Moore CA, Higashikawa M. The Physiologic Development of Speech Motor Control: Lip and Jaw Coordination. J Speech Lang Hear Res. 2000;(43):239-55.

3. Green JR, Moore CA, Reilly KJ. The Sequential Development of Jaw and Lip Control for Speech. J Speech Lang Hear Res. 2002;(45):66-79.

4. Shriberg LD, Aram DM, Kwiatkowski J. Developmental apraxia of speech: I. Descriptive and theoretical perspectives. J Speech Lang Hear Res. 1997a;(40):273-85.

5. Darley FL, Aronson AE \& Brown Jr. Apraxia para el habla: deficiencia en la programación motora del habla. In: Darley FL, Aronson AE \& Brown Jr. Alteraciones motrices del habla. Buenos Aires: Editorial Médica Panamericana; 1978. p. 248-65.

6. Metter EJ. Relação cortical dos distúrbios da fala. In: Metter EJ. Distúrbios da fala: avaliação clínica e diagnóstico. Rio de Janeiro: Enelivros; 1991. p. 179-83.

7. Crary MA. A neurolinguistic perspective on developmental verbal dyspraxia. Commun Disord. 1984;9(3):33-48.

8. Lewis BA, Freebairn LA, Hansen AJ, Iyengar SK, Taylor HG. School-age follow-up of children with childhood apraxia of speech. Lang Speech Hear Serv Sch. 2004;(35):122-40.

9. American Speech-Language-Hearing Association. Childhood Apraxia of Speech [Technical Report]. 2007. Disponível em: www.asha.org/policy.

10. Shriberg LD, Kwiatkowski J, Gruber FA. Developmental phonological disorders II: Short-term speech-sound normalization. J Speech Lang Hear Res. 1994;(37)5:112750 .

11. Hall PK, Jordan LS, Robin DA. Developmental apraxia of speech: Theory and clinical practice. Austin, TX:ProEd, 1993.

12. Thoonen G, Maassen B, Gabreels F, Schreuder R, De Swart B. Towards a standardized assessment procedure for developmental apraxia of speech. Eur J Disord Commun. 1997;(32):37-60.

13. Lewis BA, Freebairna LA, Hansena A, Taylora HG, Lyengarb S, Shriberg LD. Family pedigrees of children with suspected childhood apraxia of speech. J Commun Disord. 2004;(37):157-75

14. Von Atzingen BS. Apraxia de desenvolvimento: aspectos diagnósticos. Pró-Fono. 2002;(14):39-50.

15. Rosenbek JC, Wertz RT. Review of fifty cases of developmental apraxia of speech. Lang Speech Hear Serv Sch. 1972;(5)1:23-33. pertencentes ao nível de programação motora e de seqüenciamento pré-articulatório da fala propriamente dita.

16. Thoonen G, Maassen B, Gabreels F, Schreuder R. Features analysis of singleton consonant erros in developmental verbal dispraxia (DVD). J Speech Hear Res. 1994;(37)6:1424-40.

17. Shriberg LD, Green JR, Campbell TF, Mcsweeny JL, Scheer AR. A diagnostic marker for childhood apraxia of speech: the coefficient of variation ratio. Clin Linguist Phon 2003;(17):575-95.

18. Kent RD \& Read CT. The acoustic correlates of speaker characteristics. In: Kent RD \& Read CT. The Acoustic Analysis of Spesch. (2E). Madison, Wisconsin: Singular/ Thomson Learning, 2002. p. 189-222.

19. Shriberg LD. Research in Idiopathic and Symptomatic Childhood Apraxia of Speech. 5th International Conference on Speech Motor Control Nijmegen; 2006 June 7-10; Netherlands. Disponível em URL: http:// www.waisman.wisc.edu/phonology/

20. Shriberg LD, Aram DM, Kwiatkowski J. Developmental apraxia of speech: II. Toward a diagnostic marker. J Speech Lang Hear Res. 1997b;(40):286-312.

21. Shriberg LD, Aram DM, Kwiatkowski J. Developmental apraxia of speech: III. A subtype marked by inappropriate stress. J Speech Lang Hear Res. 1997c;(40):313-337.

22. Velleman SL, Shriberg LD. Metrical Analysis of the Speech of Children With Suspected Developmental Apraxia of Speech. J Speech Lang Hear Res. 1999;(42):1444-60.

23. Forrest K. Diagnostic criteria of developmental apraxia of speech used by clinical speech-language pathologists. Am. J. Speech-Lang. Pathol. 2003;3(2):378-80.

24. Lai CSL, Fisher SE, Hurst JA, Levy ER, Hodgson S, Fox $\mathrm{M}$, et al. The SPCH1 region on human $7 \mathrm{q} 31$ : Genomic characterization of the critical interval and localization of translocations associated with speech and language disorder. Am J Hum Genet. 2000;(67):357-68.

25. Lai CSL, Fisher SE, Hurst JA, Vargha-Khadem F \& Monaco AP. A forkhead-domain gene is mutated in a severe speech and language disorder. Nature. 2001;(413):519-23.

26. Vargha-Khadem F, Gadian DG, Copp A, Mishkin M. Foxp2 and the neuroanatomy of speech and language. Nature. 2005;(6):131-8.

27. Shriberg LD, Campbell TF, Karlsson HB, Brown RL, Mcsweeny JL, Nadler CJ. A diagnostic marker for childhood apraxia of speech: the lexical stress ratio. Clin Linguist Phon. 2003;7(17):549-74.

28. Peter B \& Stoel-Gammon C. Subsyllabic component durations in three children with suspected childhood apraxia of speech, two children with typical development, one child with phonologic delay, and one adult. Child Phonology Conference; 2003 July 1-4; Vancouver, and American Speech, Language, and Hearing Association Convention; 2003 Nov.13-15; Chicago. Disponível em: URL: http:// speechpathology.com/articles/pf_arc_disp.asp?id=238. 